\section{Guidance on clinical research involving infants, children and young people: an update for researchers and research ethics committees}

\author{
Neena Modi, ${ }^{1}$ Jyotsna Vohra, ${ }^{1}$ Jennifer Preston, ${ }^{2}$ Catherine Elliott, ${ }^{3}$ \\ William Van't Hoff, ${ }^{2}$ Jane Coad, ${ }^{4}$ Faith Gibson, ${ }^{4}$ Linda Partridge, ${ }^{5}$ \\ Joe Brierley, ${ }^{1}$ Vic Larcher, ${ }^{1}$ Anne Greenough, ${ }^{1,6}$ for a Working Party \\ of the Royal College of Paediatrics and Child Health
}

\section{BACKGROUND}

The British Paediatric Association, the forerunner of the Royal College of Paediatrics and Child Health (RCPCH), first published guidance in relation to research involving children in $1980 .^{1}$ Prior to this time, little clinical research involved children. The 1980 guidance initiated a sea change, stating 'research involving children is important', 'should be supported and encouraged' and 'research which involves a child and is of no benefit to that child (non-therapeutic research) is not necessarily either unethical or illegal'. Updated guidance was issued by the RCPCH in $2000 .^{2}$ Both documents have been cited extensively.

\section{THE NEED FOR UPDATING}

There are now many sources of detailed information for researchers, and the purpose of this paper is not to duplicate this material. The principles that underpin previous guidance remain valid, but there have been changes in their interpretation, scope and application. Since the last $\mathrm{RCPCH}$ guidance, the National Institute for Health Research (NIHR) has transformed the UK research environment. Changes in European Union regulations have facilitated children's research, including medicines studies. ${ }^{3} 4$ There have been significant changes in the UK regulation

\footnotetext{
${ }^{1}$ Royal College of Paediatrics and Child Health, London, UK; ${ }^{2}$ National Institute for Health Research Medicines for Children Research Network and Young Person's Advisory Group, Coordinating Centre, University of Liverpool, Alder Hey Children's NHS Foundation Trust, Liverpool, UK; ${ }^{3}$ Medical Research Council, London, UK; ${ }^{4}$ Royal College of Nursing, London, UK; ${ }^{5}$ WellChild, Cheltenham, Gloucestershire, UK; ${ }^{6}$ National Institute for Health Research Paediatrics (non-medicines) Speciality Group, Coordinating Centre, University of Liverpool, Alder Hey Children's NHS Foundation Trust, Liverpool, UK
}

Correspondence to Professor Neena Modi, Royal College of Paediatrics and Child Health, 5-11 Theobald's Road, London WC1X 8SH, UK; n.modi@imperial.ac.uk and governance of research, with the involvement of a number of agencies, most recently the Health Research Authority. ${ }^{5}$ There is a greater focus on involving children and their parents more actively in the design, review and conduct of studies. The ways in which society views clinical research have also continued to evolve. The Declaration of Helsinki that sets out the ethical principles that underpin medical research involving all human subjects has had two notes of clarification and seven amendments, the most recent in $2013 .^{6}$

In recognition of these changes, a working party led by the RCPCH was established with representatives from the Royal College of Nursing, Ethics and the Law Advisory Committee of the RCPCH, National Research Ethics Service, Medicines \& Healthcare Regulatory Agency, General Medical Council, Medical Research Council, WellChild, Medicines for Children Research Network (MCRN), NIHR Paediatrics (nonmedicines) Speciality Group, and NIHR MCRN Young Person's Advisory Group. The remit was to provide updated practical guidance on ethical issues in relation to research involving children. Here, we provide a summary of the areas considered.

\section{CHILDREN'S RIGHTS AND INTERESTS}

Children require protection, but this should not preclude the claim of other rights, including the right to the highest standard of healthcare, to be informed, express their views, and influence decisions made about them. ${ }^{7}$ The view of the NIHR MCRN Young Persons Advisory Group is that children should be offered the opportunity to participate in research, and have their care 'assured by research'. The current version of the Declaration of Helsinki makes no specific provision for children, ${ }^{6}$ only including a stipulation that special consideration is required for research involving vulnerable populations. The biology of many diseases, and the responses to treatments differ in children and adults, hence, conclusions extrapolated from studies in adults often have limited relevance and may be harmful. Innovative or experimental treatments are not necessarily better than existing treatments ${ }^{8}$ and without information from research there will be continuing uncertainties in the care that children receive. The RCPCH recognises the need to increase and strengthen children's research. ${ }^{9}$ The RCPCH supports the conduct of research in children that has the objectives of understanding, preventing and treating disease and preserving health. All clinical research must be reviewed and approved by a research ethics committee.

\section{RESEARCH RISK}

Every research study must be preceded by a careful assessment of predictable risks in comparison with possible benefits to the individual and the population affected by the condition. Measures to minimise risk include appropriate research design, delivery by personnel trained in the procedures to be used and experienced in caring for children, and methods to reduce the volumes of blood or tissue required. Blood sampling is often regarded as a concern in relation to the pain, and risk of research participation. However, effective anaesthetic creams are now available and sampling from indwelling lines placed as part of clinical care is painless, but expert knowledge is required of the use of these medications and the volume of blood that it is safe to take. Risk should be quantified as objectively as possible and contextualised in relation to the child's life (eg, describing the dose of radiation in terms of years of exposure to natural background radiation), and if applicable, the child's experience of the condition. The risk of the disease, treatments and clinically required procedures, should be clearly distinguished from the risk of the research.

Research should ideally carry no greater than minimal or low risk. ${ }^{2}$ However, research that involves greater than minimal risk may be acceptable if the interventions involve diagnostic procedures or treatments that are important for the individual child, and are likely to provide information that will improve understanding or treatment of the condition. Many phase 1 investigational medicinal product studies do not achieve regulatory approval because of concerns about safety and efficacy. ${ }^{10}$ In general, therefore, medicines should be tested in adults first, with testing in children 
deferred until phase 3 trials. Exceptions are situations where the condition is lifethreatening, and no alternative therapies exist; the condition is life-limiting, and all accepted therapies have failed; or where the condition has no adult analogy, and the impact is significant.

Researchers or regulators may categorise a study as 'high risk', whereas, the family may consider a risk to be reasonable if the child or other children are likely to benefit. The RCPCH strongly recommends seeking the views of children affected by the condition and their parents, about the research and the risks they regard as acceptable and reasonable.

\section{CONSENT, ASSENT AND DISSENT}

The voluntary consent of a research participant who has been provided with appropriate information, or the consent of a person legally authorised to act on their behalf, remains fundamental to the conduct of research. Formal consent must usually be obtained and documented before enrolment, and should be reaffirmed, although not necessarily in writing, at each research encounter. This is especially relevant to those studies conducted over long periods in which the child's legal status changes or where their capacity to understand information about the study matures. For children lacking capacity to provide appropriately informed consent for research, this must be obtained on their behalf from a parent, or legally authorised representative; the child's active affirmative agreement (assent) should also be sought. By the age of seven, many children are able to give assent, and lack of objection should not be construed as assent. In those with capacity, consent may be withdrawn at any time without reason and without penalty.

The acquisition of capacity is a developmental continuum, and children over 1214 years of age may have near-adult capacity. This poses potential difficulties in law. The legal test for capacity as it applies to medical treatment for those under 16 years of age, is the ability to understand what is involved and the consequences (so-called Gillick or Fraser competence). ${ }^{11}$ As there is no direct case or statute law in the UK covering nonclinical trial research, it has been presumed that the test of Gillick competence applies. In most instances, the child's assent or consent should be underpinned by parent consent, but this can be problematic where sensitive subjects, such as sexual health, contraception, and adolescent behavioural studies are involved, and there is a duty to preserve confidentiality. In such cases, the need for parental assent or consent should be carefully considered. ${ }^{12}$

The Medicines for Human Use (Clinical Trials) Regulations 2004 are the current legal basis for consent in Clinical Trials of Investigational Medicinal Products that involve children, ${ }^{4}$ though likely to be superseded by new European Union regulations in the near future. Here, a minor is defined as a child of less than 16 years of age. A person with 'Parental Responsibility', or a legally authorised representative, is required to provide consent on behalf of a 'minor,' even if $\mathrm{s} /$ he has evidential capacity, and the assent of the 'minor' should also be sought. Consent must be obtained from those over 16 years, and from participants reaching the age of 16 years during the course of a study.

Dissent is refusal to grant, or subsequent withdrawal of consent or assent. Dissent is not necessarily legally determinative, other than for Clinical Trials of Investigational Medicinal Products, especially if it places a child at risk of significant harm. However, in the context of research, dissent should be respected, even if parent consent continues.

\section{RESEARCH INVOLVING PREGNANT WOMEN}

Research involving enrolment during pregnancy may require the involvement of the newborn baby in the research protocol. There is an explicit legal requirement for a person with 'Parental Responsibility' $^{13}$ to provide consent on the behalf of a newborn baby, but lack of clarity in current guidance as to whether antenatal enrolment of a mother should be followed by additional formal written agreement for her baby to participate in any postnatal component of the study. In many circumstances, the involvement of the baby may involve no more than the use of routinely collected clinical data, or a simple procedure, such as obtaining the baby's weight or length, or sample of urine from the nappy. Alternatively it may involve a non-trivial procedure, such as a scan, blood sample, or additional outpatient attendance. The principle to be followed is that of consent as a continuing process as discussed above. The mother should have opportunity to discuss the study again with the researcher, and her on-going agreement obtained for the participation of her baby if there are further active interventions. It is recommended that there should be formal documentation if the baby is to be involved in more than non-trivial procedures. Whether her on-going agreement for her baby to be involved will be documented in writing should be made explicit in the research protocol and the research ethics committee approved information sheets.

Research in pregnancy may involve 'minors' (mothers less than 16 years of age). Here, practice in relation to consent should be based on the competence of the mother to understand the issues involved (Gillick/Fraser competence). ${ }^{11}$ The researchers should consider whether the consent or assent of the mother's mother or father, or other legal representative, is also necessary. Researchers aiming to recruit pregnant women may find it helpful to discuss these issues with experienced researchers and relevant parent groups at the planning stage.

\section{RESEARCH IN URGENT OR EMERGENCY SITUATIONS}

Research is needed to improve care in urgent and emergency situations, but should only be undertaken in these situations if absolutely necessary and if nonemergency research will not resolve the uncertainties. The Mental Capacity Act ${ }^{14}$ makes provision for research in incapacitated adults in emergency situations. It can be argued that similar considerations apply in this situation in children, and criteria that justify proceeding without initial informed consent have been developed. ${ }^{15}$ Children are particularly vulnerable to being excluded because of the difficulty in obtaining appropriately informed consent under these circumstances. ${ }^{16}$ The child, even if normally competent to make decisions, will be unable to do so, and parents, even if present, may find themselves in a position of 'situational incapacity' where their capacity is compromised by the extreme stress of the situation, the time-critical nature of the intervention, or their own condition, such as a mother after delivery under general anaesthesia. If enrolment were only possible with parental consent this would preclude the participation of many infants and children in emergency research. This is clearly undesirable and, hence, the concept of 'deferred consent' has arisen. ${ }^{17}$ Here, enrolment in emergency situations without parental consent is acceptable, if followed by explanation and information as soon as possible afterwards when formal written consent for ongoing involvement is sought, and that it is made clear that refusal for continued participation or withdrawal can take place at any time. Deferred consent is based upon the ethical principles of standard informed consent with the difference that the process is split temporally. Recent research 
has emphasised that parents are not necessarily averse to considering research participation for their children in such circumstances. ${ }^{18} 19$ However, if no parent is available, the concept of 'substituted acceptance' might apply. Here, someone else is consulted to confirm eligibility and provide consent as a 'legal representative'. This may be the doctor primarily responsible for child's treatment if she or he is not involved in study as a researcher. Consideration should be given to providing general information in advance if appropriate (eg, information about newborn resuscitation research could be provided in antenatal clinics or at booking). In all cases, the parent/carer should be provided with good information at the right time, and is then able to decide whether or not to give consent for on-going involvement.

For Clinical Trials of Investigational Medicinal Products there was no exception formerly for emergencies and consent had to be given on behalf of a minor before recruitment by a person with parental responsibility or a legal representative. ${ }^{4}$ The Medicines for Human Use (Clinical Trials) and Blood Safety and Quality (Amendment) Regulations that came into force in 2008 allows minors to be entered into a trial prior to informed consent being obtained, provided that urgent action is necessary, it is not practicable to obtain informed consent prior to enrolment, and the intervention is approved by a research ethics committee. ${ }^{20}$

\section{RESEARCH WITH PARTICULARLY VULNERABLE CHILDREN}

Children with life-threatening illnesses, looked-after children, their families, and bereaved families require a robust evidence base for both physical and psychosocial aspects of care. However, evidence remains limited and largely focussed on aspects such as symptom relief. The fear of intruding on children who are especially vulnerable, and their families, and the perceived need to provide them with extra protection has led to reluctance to involve them in research. ${ }^{21}$ However, there is now considerable evidence that families and young people who participate in research find it beneficial rather than harmful, ${ }^{22}$ with opportunity to speak about illness and death, express painful emotions, and obtain release from isolation. $^{23-26}$ There is also evidence of a 'maturational effect' of life-ending illnesses, where children and young people express a wish to benefit others, and benefit themselves from such 'meaningful' encounters. ${ }^{27}$ Research in these sensitive areas, including qualitative studies, requires review by research ethics committees that have the necessary knowledge and expertise.

\section{SEDATION FOR RESEARCH PROCEDURES}

Sedating active infants and children may be essential for some procedures, such as certain forms of respiratory function testing which, of themselves, are of minimal risk. ${ }^{28}$ Oral sedation in healthy infants and children carries minimal additional risk, and is usually associated with no more than occasional vomiting or short-lived disturbance of sleep. Children born preterm, and other at-risk groups, such as those with respiratory problems or other comorbidities may require short-stay observation facilities as they are at greatest risk of adverse effects from sedation. ${ }^{29-31}$ General anaesthesia for research purposes is normally unacceptable except where the potential benefit outweighs the risks (eg, where a tissue biopsy, imaging study or other investigation is required to assign treatment in a clinical trial of a lifethreatening or progressive illness). Researchers must justify the use of sedation, and provide evidence that appropriate monitoring will be in place during the procedure, and that they possess the necessary competencies and skills to carry out the procedures, and to deal immediately with any adverse effects. The protocol must demonstrate the importance of the study, and evidence of a rigorous riskbenefit analysis.

\section{UNEXPECTED FINDINGS DETECTED DURING RESEARCH INVESTIGATIONS}

With increasing use of new technologies, unexpected findings (Health-Related Findings) may emerge in the course of a research study, for example, from a blood test, imaging, or other investigation. The spectrum of possible findings will have varying implications, treatability and severity. Researchers have a moral responsibility, and clinician researchers may have a 'duty of care' towards research participants. Before carrying out the investigation, investigators should consider how to address such findings and, if appropriate, explain the possibility of an unexpected finding, the course of action should this occur, such as arranging for the involvement of a senior paediatrician or the participant's General Practitioner, or taking no action. As clear guidance and consensus on how Health-Related Findings should be addressed are lacking, the Medical Research Council and Wellcome Trust have provided a framework to help investigators decide on the best approach. $^{32}$

\section{COMMERCIAL SPONSORSHIP, PAYMENT OF RESEARCHERS, AND CONFLICTS OF INTEREST}

Commercial sponsorship and partnership provides an important source of research development, support and funding, and is a major component of UK government strategy for biosciences. Sponsorship from companies whose products are harmful to children, such as tobacco, alcohol or armaments, is in the view of the $\mathrm{RCPCH}$, unacceptable. A controversial area for the $\mathrm{RCPCH}$ and its members and fellows is sponsorship from the manufacturers of breast milk substitutes. ${ }^{33}$ A working party of the $\mathrm{RCPCH}^{34}$ considered these issues carefully and concluded 'Collaboration with commercial companies is important for the care of children and their families. For example, it is necessary that paediatricians should collaborate fully with research to produce drugs and other products, such as breast milk substitutes to the highest scientific standards. The College should support this process and be legitimately involved in it.' This report and recommendations were accepted by $\mathrm{RCPCH}$ Council and remain valid to this time.

Sources of research funding and potential conflicts of interest should be declared and transparent. In England, the Health Research Authority through the National Research Ethics Service has responsibility for ensuring that research ethics review is independent of sponsors, funders and academic institutions. All sponsorship arrangements should be transparent, accountable and subject to appropriate scrutiny. Clinical trials must be registered, the results published or otherwise made available, and the data disclosed within a reasonable timescale, if requested.

Financial incentives for recruitment may exert undue influence on researchers and compromise the scientific validity of a study. Financial incentives for recruiting or referring children are unacceptable. Advertisements may be helpful for recruitment and are acceptable provided that they present a truthful, balanced account of risks and potential benefits, and receive research ethics committee approval.

\section{PAYMENTS FOR PARTICIPATION OF CHILDREN IN RESEARCH}

A 'reimbursement' is payment of expenses incurred through involvement in a research study. 'Compensation payments' additionally reward participants for the time and effort of involvement in the study. 'Appreciation payments' are small tokens given after study completion. 
'Incentive payments' are designed to encourage enrolment through promise of financial gain.

Reimbursement of costs incurred through research participation, such as travel costs, is appropriate. Compensation for time spent in research participation is often offered in adult studies but controversial in children's studies because of the concern that they may undermine the voluntariness of consent, exploit weak and vulnerable subjects and create selection bias. ${ }^{35}$ However, evidence that they have these consequences or that they increase risk-taking behaviours is limited. The situation is further complicated in countries in which sections of the population have limited access to healthcare on financial grounds, and where research may provide 'free access' to a treatment they might otherwise not be able to receive.

Guidance over payments in clinical trials or other research is complex and inconsistent. The EU Clinical Trials directive prohibits incentives or financial inducements, but does permit 'compensation' without further specification. ${ }^{3}$ The Medicines for Human Use (Clinical Trials) Regulations 2004 has the same prohibition for children and their families, but appears to specify that compensation applies in the event of injury or loss. ${ }^{4}$

The UK NIHR MCRN has investigated young people's views on whether or not the offer of an appreciation payment would influence their decision to take part. Their view was that participation in simple, quick and non-invasive studies should be altruistic, and payment would not be expected. For invasive clinical studies, they expressed strong concern that any payment other than reimbursements and tokens of appreciation would be an inducement, and hence unacceptable. The nature of any token of thanks should be in proportion with the age of the child, approved by the research ethics committee, and made clear in the parent/ patient information sheets.

\section{STUDENT RESEARCH}

Research undertaken by undergraduate or postgraduate students and trainees, can provide valuable educational opportunities, but poor research serves neither student nor participant well. Students cannot be expected to undertake major research projects, nor is it justifiable to recruit participants to a study that will not produce meaningful results. However, when well integrated into the activities of a large research group, student research can provide valuable contributions to wider goals and patient benefit, for example, through acquiring pilot or feasibility data, assisting a qualified researcher with measurements, consulting user groups, and conducting systematic reviews or meta-analyses that are an essential prelude to the design of adequately powered high quality clinical trials. It is the supervisor's responsibility to ensure that extravagant claims about the research are avoided, and that there is clarity about the reasons for the project (eg, how a small, preliminary, or pilot study carried out by a student fits into a wider research strategy to benefit patients or improve knowledge or understanding). This information, and the review and approvals process that the research has received, must be made clear to participants and parents. The supervisor should attend with the student to present the study to the research ethics committee.

\section{RESEARCHER COMPETENCIES}

It is recommended that anyone involved in clinical research receives training in Good Clinical Practice, the standard to which research should be conducted ${ }^{36}$ as laid down in the Research Governance Framework for Health and Social Care 2005 that covers research in the National Health Service in England. ${ }^{37}$ Researchers working with children must be appropriately qualified by education, training and experience and able to demonstrate that they have the necessary competencies. These include an understanding of physiology, growth and development, the pharmacological properties and side effects of any medicines involved, and the methodological, ethical and legal principles underpinning the study. They must be proficient in the techniques required, possess the necessary skill and knowledge to seek informed voluntary consent from participants and their parents, demonstrate professional integrity, openness and transparency in presenting relevant conflicts of interest, and maintain complete and honest research records. It is the responsibility of researchers to ensure that they understand the regulatory framework that governs the conduct of any study to which they contribute.

\section{RESEARCH INVOLVING UK PAEDIATRICIANS CONDUCTED IN OTHER COUNTRIES}

Researchers based in the UK may lead, or be involved in, research in other countries. Research regulatory frameworks differ from country to country. The Nuffield Council of Bioethics provides guidance on research in developing countries, recommending, that in addition to evaluation of scientific validity and ethical acceptability, the relevance of the study to the healthcare priorities of the country where it is being conducted should be considered. ${ }^{38}$ UK research ethics committees are able to provide a view without delivering a formal opinion, and researchers might find it useful to consult a committee experienced in children's research for advice. In addition to meeting local requirements where these exist, UK paediatricians should conduct research in accordance with UK ethical principles and the Declaration of Helsinki, placing the well-being of the child foremost.

\section{CONCLUDING REMARKS}

The ethical principles underpinning the participation of children in clinical research have evolved over the last decades, and will continue to evolve. Recent positive developments are, greater involvement of young people and parents in all aspects of research, and appreciation that regulation, while providing protection for participants and researchers alike, and consistency of processes, is also crucial to benefit health and well-being through facilitation of high quality research. Efforts to reduce uncertainties in care through carefully conducted, methodologically rigorous, closely regulated, ethical research is an imperative that every clinician should uphold. Confidence in conduct to the highest ethical standards will help move clinical research from the exception to the norm, a necessary pre-requisite to improve children's lifelong health, and further understanding and treatment of common illnesses and rare diseases.

Acknowledgements We thank Dr Richard Hain, Professor Myra Bluebond-Langner, Dr Hugh Davies (Health Research Authority), representatives of the General Medical Council, Ms Fiona Smith (Royal College of Nursing), Mr Robert Wheeler (Chair) and members of the RCPCH Ethics and the Law Committee, for comments and advice, and Steven Kuo and Karina Pall for administrative support.

Contributors Members of the RCPCH Working Party held a series of face-to-face meetings and

corresponded by email. The first draft of the paper was prepared by NM; all authors contributed to subsequent revisions. The final draft was reviewed and approved by representatives of RCPCH Council and all authors. The full RCPCH Guidance is available at http://www.rcpch. ac.uk/research-ethics.

Funding Royal College of Paediatrics and Child Health.

Competing interests NM was RCPCH Science and Research Vice-President 2009-2014, is current President of the Neonatal Society, and Chair of the BMJ Ethics Committee; in the last 5 years. NM has held research grants awarded by the National Institute of Health Research, Welcome Trust, Medical Research Council, Acton Medical Research, Child Growth Foundation, Department of Health, Westminster Medical School Research Trust, Healthcare Quality 
Improvement Partnership, HCA International and Bliss, and has participated in academic meetings supported by Danone, Nestle, and Ferring Pharmaceuticals. AG is current RCPCH Science and Research Vice-President; in the last 5 years. AG has held grants from the National Institute of Health Research, Department of Health, National Institutes of Health and Asthma UK, and has held grants and received honoraria from various ventilator manufacturers. VL provides ethics advice as a member of a Data Monitoring Committee that reviews information from an international trial of long acting $\beta$ agonists in asthma. The trial involves four sponsors co-ordinated by a company who convened the Data Monitoring Committee at the request of the US Food and Drug Administration.

Provenance and peer review Not commissioned; internally peer reviewed.
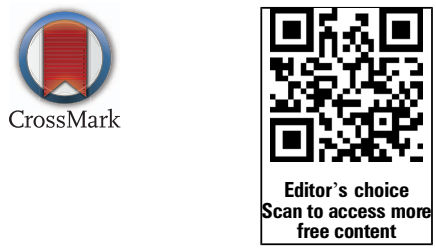

To cite Modi N, Vohra J, Preston J, et al. Arch Dis Child 2014;99:887-891.

Received 20 March 2014

Revised 17 May 2014

Accepted 20 May 2014

Published Online First 9 June 2014

Arch Dis Child 2014;99:887-891.

doi:10.1136/archdischild-2014-306444

\section{REFERENCES}

1 British Paediatric Association Working Party on Ethics of Research in Children. Guidelines to aid ethical committees considering research involving children. Arch Dis Child 1980;55:75-7.

2 Royal College of Paediatrics and Child Health Ethics Advisory Committee. Guidelines for the ethical conduct of medical research involving children. Arch Dis Child 2000;82:177-82.

3 European Clinical Trials Directive (Directive 2001/20/ EC of the European Parliament and of the Council of 4 April 2001). http://eur-lex.europa.eu/LexUriServ/ LexUriServ.do?uri=0J:L:2001:121:0034:0044:en:PDF (last accessed 13 Mar 2014).

4 Medicines for Human Use (Clinical Trials) Regulations. 2004. http://www.legislation.gov.uk/ uksi/2004/1031/schedule/1/made (last accessed $11 \mathrm{Mar}$ 2014).

5 Health Research Authority. http://www.hra.nhs.uk/ (last accessed 29 Oct 2013).

6 World Medical Association. Declaration of Helsinki, Ethical principles for the conduct of research involving human subjects. http://www.wma.net/en/30publications/ 10policies/b3/ (last accessed 8 Mar 2014).

7 United Nations General Assembly in New York: The Office of the United Nations High Commissioner for Human Rights (OHCHR). Resolution 25, session 44, Convention on the Rights of the Child November 20,
1989. http://www.ohchr.org/EN/Professionallnterest/ Pages/CRC.aspx (last accessed 29 Oct 2013)

8 Djulbegovic B, Kumar A, Glasziou PP, et al. New treatments compared to established treatments in randomized trials. Cochrane Database Syst Rev 2012;10:MR000024.

9 Modi N, Clark H, Wolfe I, et al.; for the writing group of the Royal College of Paediatrics and Child Health Commission on Child Health Research.

A healthy nation: strengthening child health research in the UK. Lancet 2013;381:73-87.

10 Shaddy RE, Denne C; for the Committee on Drugs and Committee on Pediatric Research. American Academy of pediatrics clinical report-guidelines for the ethical conduct of studies to evaluate drugs in pediatric populations. Pediatrics

2010;125:850-60.

11 Gillick v West Norfolk and Wisbech. London: House of Lords, Gillick v West Norfolk and Wisbech AHA (1986) AC 112, [1985] 3 WLR 830, [1985] 3 All ER 402, HL.

12 Collogan L, Fleshman A. Adolescent research and parental permission. In: Kodish E. ed. Ethics and research with children. New York, NY: Oxford University Press, 2005:77-99.

13 Children Act. 1989. http://www.legislation.gov.uk/ ukpga/1989/41/contents (last accessed 29 Oct 2013).

14 Mental Capacity Act. http://www.legislation.gov.uk/ ukpga/2005/9/contents (last accessed 29 Oct 2013).

15 Brierley J, Larcher V. Emergency research in children: options for ethical recruitment. J Medical Ethics 2011;37:429-32

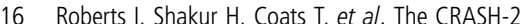
trial: a randomised controlled trial and economic evaluation of the effects of tranexamic acid on death, vascular occlusive events and transfusion requirement in bleeding trauma patients. Health Technol Assess 2013;17:1-79.

17 Maitland K, Molyneux S, Boga M, et al. Use of deferred consent for severely ill children in a multi-centre phase III trial. Trials 2011;12:90

18 Abernethy LE, Paulsen EL, Monuteaux MC, et al. Parental perceptions of clinical research in the pediatric emergency department. Pediatr Emerg Care 2013;29:897-902.

19 Gamble C, Nadel S, Snape D, et al. What parents of children who have received emergency care think about deferring consent in randomised trials of emergency treatments: postal survey. PLOS One 2012;7:e35982.

20 The Medicines for Human Use (Clinical Trials) and Blood Safety and Quality (Amendment) Regulations 2008 SI 2008/941. http://www.mhra.gov.uk/ Howweregulate/Medicines/Licensingofmedicines/ Clinicaltrials/Legislation/ImplementationofClinical TrialsDirectiveintheUK/index.htm (last accessed 15 Mar 2014).

21 Wolf J. Parents of children with serious illness are more resilient than credited. J Palliat Med 2012:15:258-9.

22 Buckle JL, Dwyer SC, Jackson M. Qualitative bereavement research: incongruity between the perspectives of participants and research ethics boards. Int J Soc Res Methodol 2010;13:111-25.
23 Kreicbergs U, Valdimarsdóttir U, Steineck G, et al. A population-based nationwide study of parents' perceptions of a questionnaire on their child's death due to cancer. Lancet 2004;364:787-9.

24 Michelson KN, Koogler TK, Skipton K, et al. Parents' reactions to participating in interviews about end-of-life decision making. J Palliat Med 2006;9:1329-38.

25 Hynson JL, Aroni R, Bauld C, et al. Research with bereaved parents: a question of how not why. Palliat Med 2006;20:805-11.

26 Stevens MM, Lord BA, Proctor MT, et al. Research with vulnerable families caring for children with life-limiting conditions. Qual Health Res 2010;20:496-505.

27 Hinds PS, Drew D, Oakes LL, et al. End-Of-Life Care preferences of pediatric patients with cancer. J Clin Oncol 2005;23:9146-5.

28 Stocks J, Modi N, Tepper R. Need for healthy controls when assessing lung function in infants with respiratory disease. Am J Respir Crit Care Med 2010;182:1340-2.

29 Sury MR, Harker H, Begent J, et al. The management of infants and children for painless imaging. Clin Radiol 2005:60:731-41.

30 Kannikeswaran N, Mahajan PV, Sethuraman U, et al. Sedation medication received and adverse events related to sedation for brain MRI in children with and without developmental disabilities. Paediatr Anaesth 2009:19:250-6.

31 Gale C, Jeffries S, Logan KM, et al. Avoiding sedation in research magnetic resonance imaging and spectroscopy in infants: our approach, success rate and prevalence of incidental findings. Arch Dis Child 2013;98:F267-8.

32 Medical Research Council and Wellcome Trust, Framework on the feedback of health-related findings in research March 2014. http://www.mrc.ac.uk/ consumption/groups/public/documents/content/ mrc009787.pdf (last accessed 17 May 2014).

33 Brady JP. Marketing breast milk substitutes: problems and perils throughout the world. Arch Dis Childhood 2012;97:529-32.

34 Commercial sponsorship in the RCPCH, Report of a Working Party, 1999. (http://www.rcpch.ac.uk/sites/ default/files/asset_library/Publications/) (last accessed 4 Jan 2013)

35 Funnell D, Fertleman C, Carrey L, et al. Quantitative valuation placed by children and teenagers on participation in two hypothetical research scenarios. J Med Ethics 2012;38:686-91.

36 Good Clinical Practice. http://www.crncc.nihr.ac.uk/ workforce_development/learning_and_development/ gcp (last accessed 29 Oct 2013).

37 Department of Health, Research Governance Framework for Health and Social Care, Second edition, 2005. https://www.gov.uk/government/ uploads/system/uploads/attachment_data/file/ 139565/dh_4122427.pdf (last accessed 11 Mar 2014).

38 http://www.nuffieldbioethics.org/research-developingcountries/research-developing- countries-summaryand-conclusions (last accessed 4 Jan 2013). 